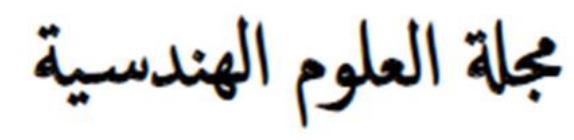

FES Journal of Engineering Sciences

\title{
Maintenance and Evaluation of Pavement for Highways
}

\author{
Ibrahim Mohamed Ahmed Ibrahim ${ }^{1, *}$ \\ 1 Civil Engineering Department, Omdurman Islamic University, Omdurman, Sudan \\ * Corresponding author: Ibrahim Mohamed Ahmed Ibrahim (e-mail: g_I ibrahim@yahoo.com). \\ Article history: Received 4 June 2020, Received in revised form 4 November 2020, Accepted 11 November 2020
}

\begin{abstract}
In-service pavement requires maintenance, it may be routine in nature, or may be major reconstruction. A pavement is designed for an assumed period, after the expiry of the design period, the pavement is likely to fail structurally and therefore, it would require a major renewal to extend it life further. Even within the service life of a pavement, the top wearing course is likely to be subjected to considerable distress due to the movement of vehicles on it. Thus the wearing course needs some routine Maintenance for smooth movements of vehicles over the pavement. The present paper introduces the reader to the Maintenance issues of a pavement. The paper is divided into sections apart from the introduction of which the first section discusses the various forms of distresses of pavement, their possible origin, and their quantification in terms of distress indices, the next two sections deal with the functional and structural evaluation of pavement their techniques, related equipment, and analysis procedures. Remedial measures to extend the longevity of pavement are discussed in the other sections while last section briefly mentions the need for evolving maintenance strategies subjected to possible fund constrains.
\end{abstract}

Keywords: Pavement, Highways, AASHTO, Sub-base, Sub-grade.

\section{INTRODUCTION}

The need for maintenance remains as a problem that all administrations of departments think about it, when projects are completed. That some problem may arise for the roads after construction, because this is related directly to traffic safety and passengers safety. The causes of accidents always find the road condition plays a roll in the accident, besides the vehicle and the driver.

Besides the importance of the traffic safety as a need for maintenance, also the economy and need for keeping the roads in good condition for nations by maintaining the roads immediately with lower cost, effort and be less danger.

\section{LITERATURE REVIEW}

1) If we look at a section of constructed road we will see the section :
These layers distribute the load evenly and smoothly to the subgrade and give the road user smooth riding surface, drains water away.

\begin{tabular}{|c|}
\hline surface \\
\hline Base \\
\hline Sub-Base \\
\hline Sub-grade \\
\hline
\end{tabular}

2) Maintenance can be divided into three areas:

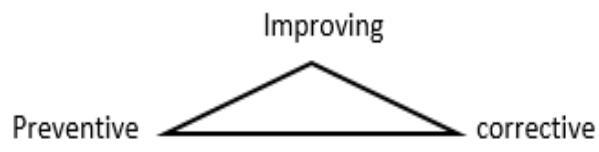

Fig. 1: illustrates the division of maintenance into three areas 
3)

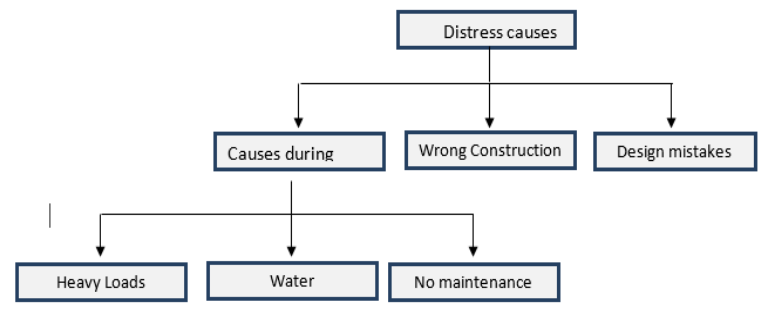

Fig. 2: distress Causes

\section{1) Distress in pavements:}

In most of the cases, the distresses in pavement are measured as the distress per unit area of the pavement. For example, one may specify a pavement as $25 \%$ cracked and $30 \%$ corrugated. In some cases, the distresses are subjective, such as corner cracks, or are expressed in some other units such as rutting which is expressed as depression measured by a 3m straight edge, or aggregate polish which is expressed in terms of bituminous surfacing can be grouped under four categories as follows:

1. Surface defects. For example fatty surface, hungry surface, smooth surface, streaking ...etc.

2. Cracks, For example, alligator cracks, longitudinal cracks, hairline cracks, shrinkage cracks, edge cracks, reflection...etc.

3. Deformations, for example rutting, corrugation, shoving, shallow depressions, settlement, heaving...etc.

4. Disintegration. e.g stripping, loss of aggregates raveling, potholes...etc.

\section{2) Functional evaluation of pavement:}

Various types and forms of pavement distresses have been mentioned. In a pavement, in fact a number of distresses may occur simultaneously, because many of the distresses are inter related, and occurrence of one may as well initiate the other.

Individual assessment and quantification of the distresses may not therefore useful. Rather, there is a need to assess the functional condition on the pavement as a whole. Table (1) illustrates the recommendations as per Indian specification for classifying pavement condition based on visual assessment. Two terms for functional assessment of pavement, were developed from
AASHTO $\{1\}$ test - present serviceability Rating (PSR) and present Serviceability index (PSI).

Table (1) Criteria for classification of pavement sections:

As a part of the functional pavement evaluation in AASHTO $\{1\}$ road test, people were asked to drive on the pavement stretch with a car of their choice, and they were asked to rate the pavement surface in a scale ranging from 0-5 later, PSI was developed which statically correlated the physical measurements on pavement conditions to the subjective judgement of human rating (PSR).

Thus, PSI is an empirical equation containing terms such as, cracked area, patched area, rut depth, and slope variance.

PSI, as the functional index of pavement condition, has some deficiencies, for example, it was developed from the evaluation of a panel of experts in the AASHTO test, and therefore, may not hold well in the present context. Also the kind of profilometers that were used in the test are not in use today.

Likewise, various other indices have been developed to quantify pavement distress as whole. Automatic equipment has been developed which can be driven over the road to acquire continuous data of functional condition of the pavement.

The acquired data is analyzed in the laboratory to extract the desired information. Roughness and skid resistance are examples.

3) Structural evaluation of pavement:

The structural evaluation of pavement can be broadly classified into two major categories, namely destructive evaluation and nondestructive evaluation (NDT) of the pavement. In non-destructive evaluation, the structural strength of the pavement is evaluated without causing any damage to the pavement or disruption of traffic.

Destructive and non-destructive evaluation of pavement are briefly discussed here:

a) In destructive evaluation, samples are received from the pavement and analyzed in the laboratory. The pits dug in the pavement give a measure of the thickness of various layers of the existing pavement, which is in turn gives an idea about the field compacted thickness compared to the thickness which was originally laid. 
TABLE (1) CRITERIA FOR CLASSIFICATION OF PAVEMENT SECTIONS

\begin{tabular}{|l|l|}
\hline Classification & Pavement condition \\
\hline Good & No cracking, rutting less than $10 \mathrm{~mm}$. \\
\hline Fair & $\begin{array}{l}\text { No cracking, or cracking confined to a single crack in } \\
\text { the wheel track with rutting between } 10 \mathrm{~mm} \text { and } \\
20 \mathrm{~mm} .\end{array}$ \\
\hline Poor & $\begin{array}{l}\text { Extensive cracking and/or rutting greater than } 20 \mathrm{~mm} \\
\text { sections with cracking exceeding 20\% shall be treated } \\
\text { failed. }\end{array}$ \\
\hline
\end{tabular}

Bitumen extraction is generally employed to check the bitumen content and aggregate gradation used in a pavement construction. The sample taken out (by core cutter or from pits) from the in-service pavement, is broken into pieces, and put into a centrifuge bitumen extractor, where bitumen is dissolved in a solvent (tricholoroethylene, benzene, methylene chloride, and so on) and is separated out from the mix by the action of centrifugal force. The quantity of bitumen is measured after the solvent is evaporated, and this gives an idea about the quantity of bitumen used in the actual construction. The aggregate proportions are also checked by sieve analysis. Correction are made for the amount of fines which goes out along with the dissolved bitumen during the extraction process. Also, necessary corrections are made for the water content, if present, in the mix.

A number of NDT devices have been developed for the structural evaluation of pavement. The NDT equipment is used to determine the [1] insitu moduli of pavement layers, [2] load transfer efficiency at joints in the concrete pavement, and [3] location and extent of void in a pavement structure. The NDT equipment used for pavement evaluation is broadly classified into four major categories on the basis of their type of loading, as briefly mentioned below:

- Static creep deflection method.

- Steady state deflection devices.

- Wave propagation devices.

- Impulsive loading devices.

4) Some major forms of distress:

1. Alligator cracking or fatigue.

2. Block cracking.

3. Corner break and spoil.

4. Corrugation.

5. Depression.

6. Fatty surface or bleeding.

7. Hairline crack on bituminous pavement surface.
8. Hungry surface.

9. Lane \shoulder Drop-off or Heave.

10. Loss of aggregates.

11. Patch.

12. Polished aggregate or smooth surface.

13. Potholes.

14. Reflection cracking.

15. Raveling.

16. Ratting.

17. Slippage.

18. Streaking.

19. Stripping.

20. Swell and blow up.

21. Pavement roughness.

22. Skid resistance.

\section{RESULTS AND DISCUSSION}

a) Find the causes of distress before they become dangerous and they maintain the section.

b) Preparation of materials, equipment's, tools, and qualified team.

c) Keep the main appearance of the site in good condition.

d) To reduce the time of closure of the road.

e) Keeping the road on its duration of design period and also increase that period.

f) Cater for traffic safety and decrease of accidents.

g) Reduction of cost of materials and labors. Types:

a- Programed inspection.

b- An expected inspection.

c- Administrative inspection.

Scientific work should be done in maintenance work.

The distressed place should be prepared,

(Cleaning, shaping) then work is started

- Repair of minor distresses (pot holes, patchs).

- Overlay.

- Reconstruction.

- Best engineer must be selected and trained staff.

This will increase the life time of the road, and economically it is sounding. 


\section{CONCLUSIONS}

1. The department of maintenance should be on the same level and importance of the departments.

2. It should has a reasonable budget and equipment's.

3. A plan for maintenance should be prepared.

4. Inspection should be done before the work.

\section{APPENDIX}

Some pictures show the problems and highway maintenance:
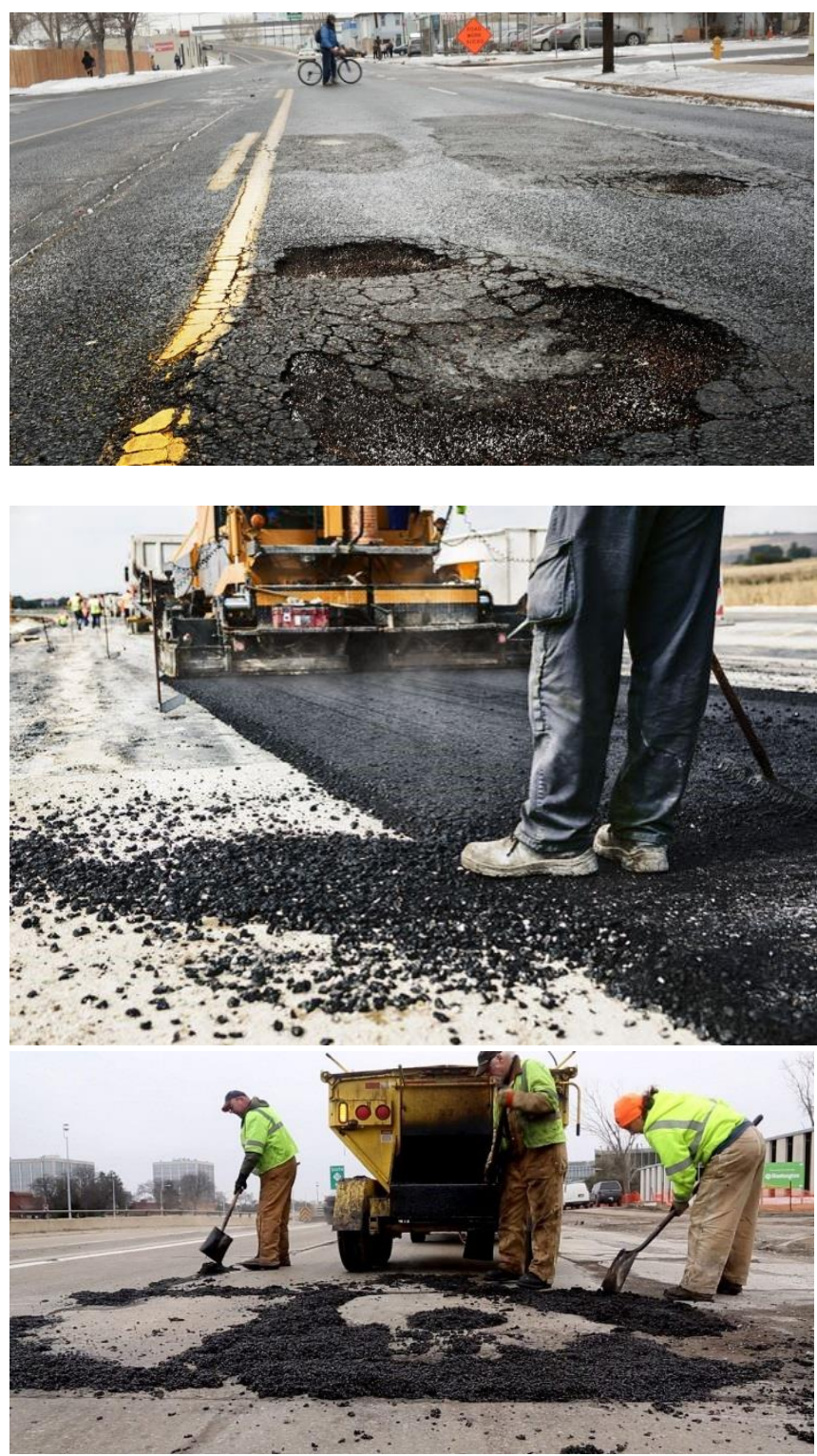

\section{REFERENCES}

[1] AASHTO maintenance of Bituminous Surfaces of highways IRC. 8: 1982.

[2] Gide lines for strengthening of Flexible Road Pavements using Benkel Man Beam Deflection Technique. IRC: 81-1981. The Indian Road Congress, New Delhi 1997.

[3] Gide for Design of pavement Structures American Association of state Highway officials Washington, D,C, 1993.

[4] Code of Practice for

[5] Khana, S,K, Highway Engineering, Nem Chand, publisher, Roorkee India-

[6] Tentative Guide lines for structural strength Evaluation of Rigid Airfield pavement. IRC: 76-1979. The Indian Roads Congress, New Delhi 1980.

[7] The little Book of profiling, Research Publication University of Michigan.

[8] Yang H, Hauning pavement analysis and design, Prentice Hall, 1993.

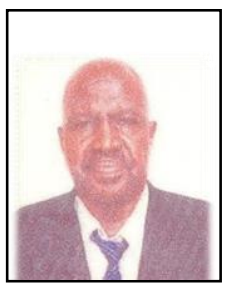

Dr. Ibrahim Mohamed Ahmed Ibrahim, He was born in El Fasher in the year 1955.

He obtained a Bachelor's degree in civil engineering from University of Pune, Republic of India in the year 1978, also a Master's in civil engineering from Rocky University of the Republic of India (Roads and Airports) in 1982, and obtained Doctorate in civil engineering from the University of Sudan in the year 2004.

$\mathrm{He}$ is a Member of the Sudanese Engineering Society, also a Member of the Indian Civil Engineering Society, a Member of the Indian Roads Council, a Member of the Khartoum State Engineers Union, and a Member of Committee of Roads and Bridges of National organization of specification. 